\title{
Evidence for a Protective Role of Pulmonary Surfactant Protein D (SP-D) against Influenza A Viruses
}

\author{
Kevan L. Hartshorn, ${ }^{*}$ Edmond C. Crouch, ${ }^{\star}$ Mitchell R. White, ${ }^{\star}$ Paul Eggleton, ${ }^{*}$ Alfred I. Tauber, ${ }^{*}$ Donald Chang, ${ }^{\star}$ and \\ Kedarnath Sastry* \\ ${ }^{*}$ Departments of Medicine and Pathology, Boston University School of Medicine, Boston, Massachusetts 02118; and ${ }^{\ddagger}$ Department of \\ Pathology, Washington University School of Medicine, St. Louis, Missouri 63110
}

\begin{abstract}
We tested the hypothesis that pulmonary surfactant-associated lectins - surfactant proteins $A$ and D (SP-A, and -D) contribute to initial protective mechanisms against influenza A viruses (IAVs). SP-D potently inhibited hemagglutination activity of several strains of IAV as well as causing viral aggregation. SP-D enhanced neutrophil binding of IAV and neutrophil respiratory burst responses to the virus. Neutrophil dysfunction resulting from IAV exposure was diminished when the virus was pre-incubated with SP-D. Each of these effects was mediated by the calcium-dependent carbohydrate-binding property of SP-D. Native SP-D preparations of both human and rat origin, as well as recombinant rat SP-D, had similar activity. SP-A also inhibited IAV hemagglutination activity. We have previously reported that related mammalian serum lectins (mannose-binding lectin [MBL] and conglutinin) have similar effects. SP-D was at least 10-fold more potent at causing hemagglutination inhibition than were SP-A or MBL. SP-D was shown to contribute to potent anti-IAV activity of human bronchoalveolar lavage fluid. These results suggest that SP-D-alone, and in conjunction with SP-A and phagocytic cells-constitutes an important component of the natural immune response to IA V infection within the respiratory tract. (J. Clin. Invest. 1994. 94:311-319.) Key words: influenza virus • neutrophil - surfactant protein D • surfactant protein A - hemagglutination
\end{abstract}

\section{Introduction}

Surfactant protein D (SP-D) ${ }^{1}$ is a member of the collectin subgroup of the mammalian C-type lectin superfamily, which includes another surfactant protein, surfactant protein A (SP-A), and at least two serum proteins, mannose-binding lectin (MBL), and conglutinin $(1,2)$ : Each of these lectins has been shown to bind to a variety of microorganisms, and may have a role in host defense responses, both through inhibiting infecti-

Address correspondence to K. L. Hartshorn, Boston University School of Medicine, 80 East Concord St., Boston, MA 02118. 1994.

Received for publication 11 June 1993 and in revised form 18 March

1. Abbreviations used in this paper: $\mathrm{HA}$, hemagglutinin; IAV, influenza A virus; MBL, mannose-binding lectin; SP, surfactant protein.

J. Clin. Invest.

(c) The American Society for Clinical Investigation, Inc.

0021-9738/94/07/0311/09 \$2.00

Volume 94, July 1994, 311-319 vity of various organisms directly, and by enhancing phagocyte activation (3-9). The evidence for this is strongest with MBL, in that low levels of this protein have been associated with a syndrome of increased susceptibility to infection during infancy (2). We have previously reported that MBL and conglutinin inhibit the infectivity and hemagglutination (HA) activity of influenza A viruses (IAV) by binding to carbohydrates present on the viral HA molecule $(10,11)$. These lectins also act as opsonins, promoting neutrophil activation in response to IAV. The strong structural relationship of these lectins with SP-D (e.g., $66 \%$ amino acid sequence identity of human SP-D with conglutinin) $(12,13)$, and the fact that SP-D accumulates in the lower respiratory tract at sites suitable to interact with IAV in vivo (14), prompted us to examine the activity of SP-D against IAV in vitro.

The collectins naturally occur as multimeric structures resembling Clq in having collagenous domains which tether multiple globular carbohydrate recognition domains $(2,15)$. SP-D is produced by alveolar type II pneumocytes and by Clara cells (nonciliated bronchiolar cells) (14). It has been shown to be a major $E$. coli binding protein in bronchoalveolar lavage fluid, and can bind to and aggregate a range of bacteria via its calciumdependent, carbohydrate binding activity (8). Rat and human SP-D have very similar sugar binding specificity and have similar interactions with bacteria $(8,12)$. In addition, SP-D has been shown to bind to alveolar macrophages (16) and to stimulate a chemiluminescence response in these cells (9).

We here report that SP-D of human and rat origin share with MBL and conglutinin the ability to potently inhibit HA activity of a variety of strains of IAV, and to enhance neutrophil activation by IAV.

\section{Methods}

Reagents. Formylmethionylleucylphenylalanine (FMLP), cytochalasin B, horseradish peroxidase-Type II, scopoletin, superoxide dismutase (SOD), cytochrome-C, maltose, Ficoll, dextran, sodium citrate, maltosyl-agarose, and citric acid were purchased from Sigma Chemical Co. (St. Louis, MO) and Hypaque was obtained from Winthrop Pharmaceuticals (Des Plaines, IL). Dulbecco's phosphate-buffered saline with or without $\mathrm{Ca}^{2+}$ or $\mathrm{Mg}^{2+}$ was purchased from Flow Labs (McClean, VA). Tris buffered saline contained either $2 \mathrm{mM} \mathrm{Ca}^{2+}$ or $10 \mathrm{mM}$ EDTA, as indicated.

$S P-D$ preparation. Native rat SP-D was isolated from the $10,000 \mathrm{~g}$ supernatant of bronchoalveolar lavage from silicotic rats (17). Human SP-D was isolated from the supernatant of lavage obtained from patients with human alveolar proteinosis (18). In each case, SP-D was purified by sequential saccharide affinity chromatography on maltosyl-agarose, and gel-filtration on 4\% agarose (A15M; Bio Rad Laboratories, Richmond, CA). Rat SP-D showed a single disulfide-bonded component of $43 \mathrm{kD}$ (reduced) after resolution by SDS-PAGE and silver staining. The human SP-D preparation showed a major band of $43 \mathrm{kD}$ (reduced), and minor components corresponding to SP-D dimers, trimers and 


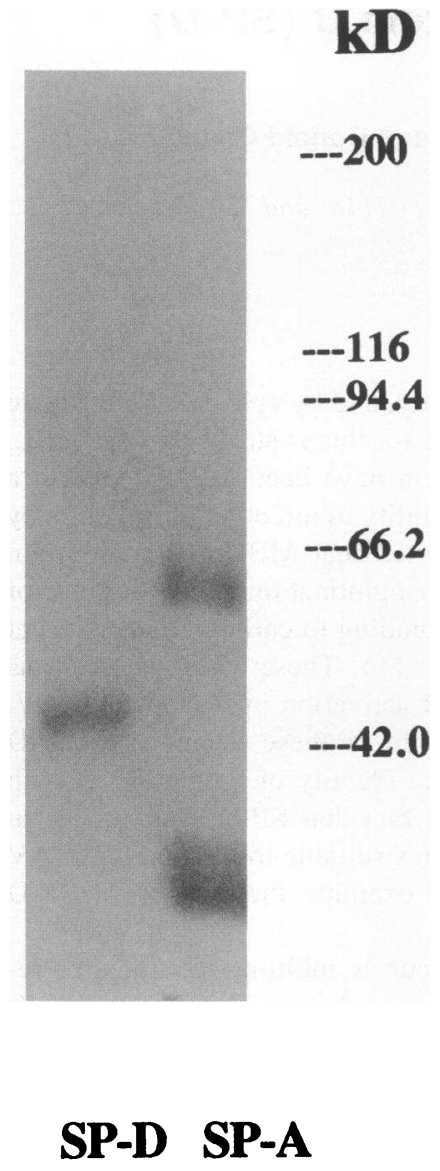

Figure 1. SDS/PAGE of purified native human SP-D and SPA. Human alveolar proteinosis SP-A and SP-D were reduced with 5\% mercaptoethanol, followed by loading of 1 and 10 $\mu \mathrm{g}$, respectively, of the reduced SP-D and SP-A onto a $10 \%$ polyacrylamide gel. The gel was developed with Coomassie blue.

higher aggregates. The procedures for purification of these proteins have been previously published in greater detail $(17,18)$. As established in those publications these SP-D preparations were free of contamination with other proteins including SP-A based on SDS-PAGE and immunoblotting analysis.

Recombinant rat SP-D was derived from a full length clone of rat SP-D cDNA stably expressed in CHO K1 cells. The protein comigrated with native rat SP-D on SDS-PAGE under reducing and nonreducing conditions, showed the expected shift in apparent molecular mass after incubation with endoglycosidase $\mathrm{F}$, bound efficiently to maltosyl-agarose, and eluted at the expected position on nondenaturing gel filtration chromatography. A more detailed description of the expression and purification of this protein is in preparation.

Human surfactant protein A (SP-A) was graciously provided by Drs. Virginia Shepherd and Zissis Chroneos (Vanderbilt University, Nashville, TN). The SP-A was purified from alveolar proteinosis patients as described (19) and was shown to be at least $95 \%$ pure by SDS-PAGE analysis and by ${ }^{125} \mathrm{I}$ labeling followed by SDS-PAGE and autoradiography. Fig. 1 depicts the appearance of the SP-A used in these studies on SDS-PAGE. An additional lane showing the migration of native human SP-D is included for comparison. Note that the SP-A appears as a broad band of $\sim 26-36 \mathrm{kD}$ as well as another band of $\sim 62 \mathrm{kD}$. This is the typical appearance of purified SP-A derived from alveolar proteinosis patients when analyzed by SDS-PAGE under reducing conditions (19). Previous studies have demonstrated with amino acid sequencing and other methods that these bands represent monomeric and dimeric forms of SP-A (20).

Bronchoalveolar lavage (BAL) fluids were obtained from healthy volunteer donors with informed consent as approved by the Boston University School of Medicine Institutional Review Board for Human Research. Between 150 and $200 \mathrm{ml}$ of normal saline was instilled for the lavage. Fluids retrieved from this procedure were subjected to an initial low speed centrifugation $(150 \mathrm{~g})$ to remove cells and other large particulates. Further processing of the fluid was carried out as described below.

The ELISA assay to measure SP-D levels employed native human SP-D and the immunoglobulin fraction of a well-characterized rabbit anti-SP-D antiserum (8) to establish a standard curve. The assay detected concentrations between 5 and $250 \mathrm{ng} / \mathrm{ml}$ of human SP-D in a linear manner. Purified SP-D or BAL fluids were coated overnight on microtiter wells, then washed three times with PBS-Tween followed by blocking of nonspecific binding sites with $0.25 \%$ BSA in PBS-Tween. After further washing, the wells were incubated for $2 \mathrm{~h}$ with a 1:1,000 dilution of the anti-SP-D immunoglobulin preparation. After washing, a 1:1,000 dilution of goat anti-rabbit polyclonal IgG conjugated to horseradish peroxidase (HRP; Sigma Chemical Co.) was then added for $2 \mathrm{~h}$, followed by washing and development using TMB peroxidase substrate (Bio Rad Laboratories). The reaction was stopped using $\mathrm{H}_{2} \mathrm{SO}_{4}$, and absorbance read at $450 \mathrm{~nm}$. All samples were run in duplicate. Protein assays were performed using BCA protein assay according to manufacturer's specifications (Sigma Chemical Co.).

Binding of purified SP-D, or of SP-D present in BAL fluid, to IAV was assessed by a dot blot assay. Twofold dilutions of purified IAV


Separations Inc., Westboro, MA) and allowed to air dry. The virus dilution buffer was PBS containing $200 \mu \mathrm{g} / \mathrm{ml}$ of bovine serum albumin (BSA). Blots containing the dilution buffer and/or secondary antibody alone were included. The dried strips were then immersed in 5\% nonfat dry milk in TBS for $1 \mathrm{~h}$ at room temperature. After washing twice in TBS containing $0.3 \%$ Tween, the strips were incubated with either purified SP-D $(200 \mathrm{ng} / \mathrm{ml})$ or BAL samples for $18 \mathrm{~h}$ at $4^{\circ} \mathrm{C}$. After washing again twice in TBS containing $0.3 \%$ Tween, the strips were incubated in TBS with 5\% milk containing a 1:500 dilution of rabbit anti-SP-D IgG for $1 \mathrm{~h}$ at room temperature. After further washing, the strips were incubated with TBS containing a 1:1,000 dilution of goat anti-rabbit IgG conjugated to HRP for $1 \mathrm{~h}$ at $37^{\circ} \mathrm{C}$. Peroxidase activity was detected using a chemiluminescence reaction (ECL System; Amersham, U.K.).

Virus preparation. Virus stocks were grown in the chorioallantoic fluid of 10-d-old embryonated hen's eggs, and purified on a discontinuous sucrose density gradient as previously described $(21,22)$. Virus stocks were suspended in Dulbecco's modified phosphate-buffered saline (PBS), aliquoted and stored at $-70^{\circ} \mathrm{C}$ until used. Potency of each virus stock was measured by hemagglutination assay, and titers of $1: 8,000$ through 1:32,000 (as indicated) hemagglutination units (HAU) were measured after samples were thawed from storage at $-70^{\circ} \mathrm{C}$. Hemagglutinin (HA) titers were determined by titration of virus samples in PBS followed by addition of thoroughly washed human type $O$ red blood cells. The A/Texas 77/H3N2 (Texas 77) and A/PR/8/34/H1N1 (PR8) strains of IAV were gracious gifts of Dr. Jon Abramson (Bowman-Gray School of Medicine, Winston-Salem, NC). The A/Brazil78/ $\mathrm{H} 1 \mathrm{~N} 1$ (Brazil 78) and $\mathrm{A} / \mathrm{Mem} 71_{\mathrm{H}}-\mathrm{Be} 1_{\mathrm{N}}$ strains were kindly provided by Dr. E. Margot Anders (University of Melbourne, Melbourne, Australia) (23). The A/Bangkok 79/H3N2 (Bangkok 79) strain was a gift of Robert Webster, M.D. (St. Jude's Hospital, Memphis, TN).

Incubation of SP-Ds with IAV stocks was carried out at $37^{\circ} \mathrm{C}$ in TBS with $2 \mathrm{mM} \mathrm{Ca}^{2+}$ except in indicated experiments in which maltose was added, or in which the buffer contained $10 \mathrm{mM}$ EDTA and no added $\mathrm{Ca}^{2+}$. Where maltose was used to inhibit the carbohydrate binding activity of SP-D (or SP-A) the lectins were pre-incubated with 167 $\mathrm{mM}$ maltose for $15 \mathrm{~min}$ before adding the lectin to IAV. Preliminary experiments (data not shown) demonstrated that this concentration of maltose maximally reduced the HA inhibitory activity of SP-D without altering HA activity of the virus in the absence of SP-D or affecting neutrophil functions. In the former case, SP-D stocks were maintained in $10 \mathrm{mM}$ EDTA and recalcified just prior to assays to minimize SP-D self-aggregation. Prior to incubation of the lectin with the virus, a low speed ( $150 \mathrm{~g}$ for $5 \mathrm{~min}$ ) centrifugation of the virus preparation was carried out to remove any viral aggregates. 
Assessment of virus aggregation. Virus aggregation was assessed by measuring changes in light transmission through suspensions of IAV after addition of various concentrations of SP-D. These measurements were performed on an SLM/Aminco 8000C (SLM Instruments, Urbana, IL) spectrofluorometer. The excitation and emission wavelengths were $350 \mathrm{~nm}$ and slits at $16,0.25,0.25,2$, and $2 \mathrm{~nm}$. Previous experiments have established that a decrease in light transmission of vesicles in the size range of IAV particles indicates particle aggregation $(24,25)$. Addition of SP-D to virus-free buffer containing $2 \mathrm{mM} \mathrm{Ca}^{2+}$ did not cause any decrease in light transmission.

Measurement of neutrophil activation. Neutrophils from healthy volunteer donors were isolated to $>95 \%$ purity as previously described using dextran sedimentation, followed by a Ficoll-Hypaque gradient centrifugation for removal of mononuclear cells, and hypotonic lysis to eliminate contaminating erythrocytes (21). Cell viability was $>98 \%$ as determined by trypan blue staining, and cells were used within five hours of isolation. $\mathrm{H}_{2} \mathrm{O}_{2}$ production was measured by the oxidation of scopoletin, and $\mathrm{O}_{2}^{-}$assessed by the continuous monitoring of the SOD inhibitable reduction of cytochrome $\mathrm{C}$ as previously detailed (26). Neutrophil deactivation was assessed by first incubating cells with IAV for $10 \mathrm{~min}$., followed by measurement of $\mathrm{O}_{2}^{-}$production in response to FMLP $(10,21)$.

Measurement of influenza virus binding to neutrophils. Viral binding to neutrophils was measured by preparing FITC-labeled virus and incubating this preparation with neutrophils, followed by evaluation of cell associated fluorescence using a flow cytometer. FITC stock was prepared at $1 \mathrm{mg} / \mathrm{ml}$ in $1 \mathrm{M}$ sodium carbonate, $\mathrm{pH}$ 9.6. The FITC labeled virus was prepared by incubating concentrated virus stocks with FITC (10:1 mixture by volume of virus in PBS with FITC stock) for $1 \mathrm{~h}$, followed by dialysis of the mixture for $18 \mathrm{~h}$ against PBS. For fluorescence measurements, concentrated FITC-labeled virus was incubated for $30 \mathrm{~min}$ at $37^{\circ} \mathrm{C}$ with control buffer or various amounts of SP-D, followed by addition of 10- $\mu \mathrm{l}$ aliquots of these samples to neutrophils $\left(10^{6}\right.$ cells in $100 \mu \mathrm{l}$ TBS containing either $2 \mathrm{mM} \mathrm{Ca}^{2+}$ or $10 \mathrm{mM}$ EDTA, as indicated). In some samples SP-D was pre-incubated with maltose ( $167 \mathrm{mM}$ ) before mixing SP-D with virus. After allowing virus and neutrophils to interact for $15 \mathrm{~min}$ at $4^{\circ} \mathrm{C}$, the neutrophils were washed, resuspended in virus-free PBS and fixed with $2 \%$ paraformaldehyde. Cell associated fluorescence was measured on a Becton-Dickinson FACS Scan 2 and analyzed using the Lysis II program.

\section{Results}

Effect of incubation with SP-Ds on hemagglutination activity of IAV. As presented in Table I, native rat and human SP-D inhibited HA activity of all $\mathrm{H} 3$ strains of IAV tested in a $\mathrm{Ca}^{2+}$ dependent manner. Recombinant rat SP-D had similar HA inhibitory effects. The Brazil 78 strain of IAV which is of the H1 subtype was also inhibited by the SP-Ds. If SP-Ds were pre-incubated with maltose they lost the ability to inhibit IAV HA activity. In contrast, pre-incubation with $\geq 160 \mathrm{mM}$ of either galactose or $\mathrm{N}$-acetyl glucosamine did not reduce HA inhibitory effects of SP-D (data not shown). These results indicate that $\mathrm{HA}$ inhibition by SP-D was mediated by its $\mathrm{Ca}^{2+}$ dependent, lectin activity, and are compatible with the known carbohydrate-binding specificities of SP-D. SP-D had much less activity against the PR-8 H1N1 strain of IAV (see Table I). The PR-8 strain of IAV differs from H3 strains in that it lacks high mannose oligosaccharide attachments on its HA and has no carbohydrate attachment near the sialic acid binding site $(27,28)$.

Another approach was taken to characterizing the HA inhibitory effects of the SP-Ds that involved pre-incubation of much more concentrated preparations of IAV with escalating doses of the SP-Ds, followed by measurement of HA activity. As
Table I. Inhibition of Hemagglutination of Various Strains of IAV after Incubation with Rat or Human SP-D

\begin{tabular}{lccr}
\hline & \multicolumn{3}{c}{ SP-D concentration causing HA inhibition (ng/ml) } \\
\cline { 2 - 4 } & TBS + $\mathrm{Ca}^{2+}$ & $\begin{array}{c}\text { TBS }+\mathrm{Ca}^{2+} \\
+ \text { maltose }\end{array}$ & TBS + EDTA \\
\hline Native Rat SP-D & & & \\
Texas 77(H3N2) & 95 & $>690$ & $>690$ \\
Bangkok 79(H3N2) & 95 & $>2750$ & $>2750$ \\
Mem71 $_{\mathrm{H}-\text {-Bel }_{\mathrm{N}}(\mathrm{H} 3 \mathrm{~N} 1)}$ & $290 \pm 60$ & $>690$ & $>690$ \\
Brazil 78(H1N1) & $170 \pm 3$ & & $>1800$ \\
PR-8 34(H1N1) & 2750 & & $>2750$ \\
Recombinant Rat SP-D & & & \\
Texas 77(H3N2) & 143 & & $>300$ \\
Native Human SP-D & & & $>300$ \\
Bangkok 79(H3N2) & 38 & $>300$ & \\
Mem71 -Bel $_{\mathrm{N}}(\mathrm{H} 3 \mathrm{~N} 1)$ & 75 & & \\
Brazil 78(H1N1) & 75 & & \\
\hline
\end{tabular}

HA inhibition was determined by serially diluting native rat or human rat SP-D in 96 well plates, followed by addition of $40 \mathrm{HAU} / \mathrm{ml}$ of the indicated strains of IAV. TBS $+\mathrm{Ca}^{2+}$ indicates that the experiment was carried out in TBS containing $2 \mathrm{mM}$ of $\mathrm{Ca}^{2+}$. TBS + EDTA indicates that $10 \mathrm{mM}$ EDTA was present throughout the experiment. TBS $+\mathrm{Ca}^{2+}$ + maltose indicates that the SP-D was pre-incubated with $167 \mathrm{mM}$ maltose prior to being added to virus. After incubation of viruses with SP-D, $50 \mu \mathrm{l}$ of a washed suspension of human Type $O$ red blood cells was added to each well. The values given represent the mean \pm SEM of two to three determinations of the minimal concentration of SP-D required to fully inhibit hemagglutination by this amount of virus. (Where no SEM is given replicate values were identical. Where the highest concentration tested did not inhibit hemagglutination this is indicated as such [e.g., $>2,750 \mathrm{ng} / \mathrm{ml}]$.)

depicted in Fig. 2, both native rat and human SP-D caused doserelated inhibition of $\mathrm{HA}$ activity $\left(\mathrm{ID}_{50} \mathrm{~s}\right.$, respectively, 1.5 and 3 $\mu \mathrm{g} / \mathrm{ml}$ ). For recombinant rat SP-D the $\mathrm{ID}_{50}$ for HA activity of a similar concentration of IAV was $3.1 \mu \mathrm{g} / \mathrm{ml}$ (mean of four experiments; data not shown). The HA inhibitory effects were dependent on calcium, and inhibitable by pre-incubation of the lectins with maltose. Aliquots of these concentrated virus preparations treated with various doses of lectins were then used in assays of neutrophil binding to IAV (see below).

Rat and human SP-D cause aggregation of IAV. As depicted in Fig. 3, when either native rat or human SP-D were added to a stirred suspension of Texas $77 \mathrm{IAV}$ in the presence of $2 \mathrm{mM}$ $\mathrm{Ca}^{2+}$, a rapid decline in light transmission through the solution occurred. The effects of human and rat SP-D on light transmission were not seen in the presence of $10 \mathrm{mM}$ EDTA. Preincubation of native rat SP-D with $167 \mathrm{mM}$ maltose also abolished the effect. These findings indicate that SP-D aggregates IAV particles principally by binding to viral carbohydrates. Viral HA binding to carbohydrates on SP-D is unlikely, since HA binding to sialic acids is unaffected by $\mathrm{Ca}^{2+}$ chelation (29) (see Table I). In addition, the concentrations of maltose used in these experiments do not inhibit HA activity (see Table I). Recombinant rat SP-D caused similar aggregation of the Texas 77 strain of IAV in $\mathrm{Ca}^{2+}$-containing buffer. Maximal aggregation was achieved with either $613 \mathrm{ng} / \mathrm{ml}$ or $1.18 \mu \mathrm{g} / \mathrm{ml}$ of the recombinant protein in three experiments (data not shown).

$S P D$ enhances neutrophil binding of IAV. Results of experi- 

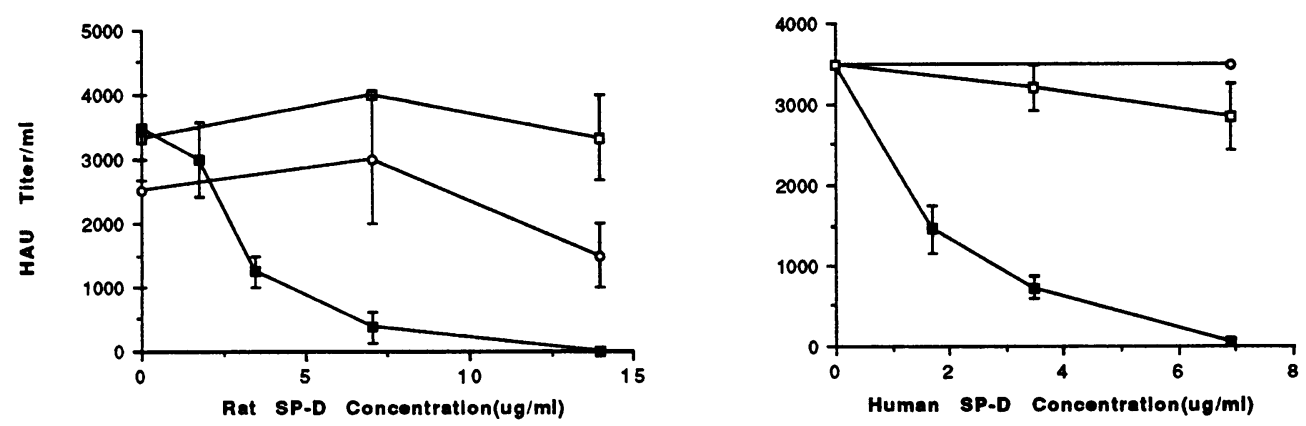

Figure 2. SP-D inhibits the hemagglutination activity of IAV. HA titers of concentrated Bangkok 79 IAV alone or after incubation with various amounts of native rat or human SP-D (left and right pan$e l s$, respectively) are shown. Results represent mean \pm SEM of four experiments in which Bangkok $79 \mathrm{IAV}$ was pre-incubated for $30 \mathrm{~min}$ at $37^{\circ} \mathrm{C}$ in control buffers or buffers containing the indicated amounts of SP-D, followed by determination of HA titer using hu-

man type $O$ red cells. Solid squares and open circles represent samples incubated in TBS with $2 \mathrm{mM} \mathrm{Ca}{ }^{2+}$ and TBS with $10 \mathrm{mM}$ EDTA, respectively. Open squares represent samples incubated in TBS with $2 \mathrm{mM} \mathrm{Ca}^{2+}$ also, but in this case SP-D was pre-incubated with $167 \mathrm{mM}$ maltose before to addition of virus. (This amount of maltose did not alter the HA activity of IAV in the absence of SP-D). HA activity was significantly inhibited $(P \leq 0.01)$ by $3.5 \mu \mathrm{g} / \mathrm{ml}$ rat SP-D or greater, but only in TBS with $2 \mathrm{mM} \mathrm{Ca}^{2+}$ without maltose. Human SP-D significantly reduced $(P \leq 0.01)$ HA titers at all concentrations tested, including $1.7 \mu \mathrm{g} / \mathrm{ml}$, but again only in TBS with $2 \mathrm{mM} \mathrm{Ca}^{2+}$ without maltose.

ments testing the effects of SP-D on IAV binding to neutrophils are depicted in Fig. 4. A concentrated stock of FITC-labeled Bangkok 79 IAV was pre-incubated with various concentrations of SP-Ds as described in Fig. 2, followed by addition of aliquots of these preparations to a suspension of neutrophils. As assessed by mean cell fluorescence, native rat SP-D caused a marked increase in viral binding to the neutrophil, which was most pronounced where virus stock had been pre-incubated with 7 $\mu \mathrm{g} / \mathrm{ml}$ of SP-D. Recombinant rat SP-D $(5.9 \mu \mathrm{g} / \mathrm{ml})$ also enhanced IAV binding when tested in a similar manner in three experiments (data not shown). Human SP-D caused optimal binding enhancement at $3.5 \mu \mathrm{g} / \mathrm{ml}$, and significantly increased binding at $1.7 \mu \mathrm{g} / \mathrm{ml}$.

The effects of native rat and human SP-Ds on viral binding to neutrophils were abrogated if the SP-D was pre-incubated with maltose prior to incubation with IAV, or if the experiments were carried out in EDTA (Fig. 4). EDTA had no effect on viral binding to neutrophils in the absence of SP-D. Since these experiments were carried out at $4^{\circ} \mathrm{C}$, the values represent viral binding without internalization. Note that the concentrations of SP-D given are those used during pre-incubation with concentrated IAV ( $3500 \mathrm{HAU} / \mathrm{ml})$ before dilution for incubation with neutrophils. The final concentrations of SP-D present upon incubation with neutrophils were 10 -fold less.

$S P-D$ enhances neutrophil activation by IAV. As shown in Fig. 5, pre-incubation of Texas 77 IAV with native rat SP-D causes a marked enhancement of the ability of the virus to stimulate neutrophil $\mathrm{H}_{2} \mathrm{O}_{2}$ production. The samples used in these experiments were the same as those used in assessing virus aggregation (see Fig. 3). Maximal respiratory burst enhancement occurred at $366 \mathrm{ng} / \mathrm{ml}$ (final concentration) of native rat SP-D. Two similar experiments were performed using recombinant rat SP-D. Pre-incubation of Texas 77 IAV with $613 \mathrm{ng} /$ $\mathrm{ml}$ of the recombinant protein increased the neutrophil $\mathrm{H}_{2} \mathrm{O}_{2}$ response from $0.06 \pm 0.01$ (for untreated IAV) to $0.3+0.05$ nmoles $/ 3 \mathrm{~min} / 4 \times 10^{6}$ neutrophils.

Human SP-D had a similar ability to enhance neutrophil $\mathrm{H}_{2} \mathrm{O}_{2}$ production in response to IAV. Fig. 6 depicts representative tracings of neutrophil $\mathrm{H}_{2} \mathrm{O}_{2}$ production (as assessed by the scopoletin fluorescence assay) in response to IAV alone, or IAV which had been treated with various concentrations of human SP-D. Maximal enhancement of $\mathrm{H}_{2} \mathrm{O}_{2}$ production occurred at $125 \mathrm{ng} / \mathrm{ml}$ of human SP-D in three experiments. Note that these results parallel those obtained in testing the ability


Figure 3. SP-D promotes aggregation of IAV. Changes in percent light transmission occurring upon addition of SP-D to a stirred suspension of Texas 77 IAV ( $500 \mathrm{HAU} / \mathrm{ml}$ ) Either native rat (left panel) or human SP-D (right panel) was added at 300 s. Assays were performed in TBS with $2 \mathrm{mM}$ $\mathrm{Ca}^{2+}$, except where EDTA is indicated, in which case the assay was performed in TBS with $10 \mathrm{mM}$ EDTA. Except for assays in EDTA, SP-D (which is stored in TBS containing $10 \mathrm{mM}$ EDTA) was recalcified immediately before assay. Results represent mean \pm SEM of three similar experiments for the $366 \mathrm{ng} /$ $\mathrm{ml}$ dose of rat SP-D, and the 125 and $250 \mathrm{ng} / \mathrm{ml}$ doses of human SP-D. The decline in light transmission 5 min. after addition of SP-D was significant $(P \leq 0.01)$ for these samples. The remaining experiments are representative of two performed. In tracings designated " $E D T A$ " 586 and $400 \mathrm{ng} / \mathrm{ml}$ of rat and human SP-D, respectively, were added at $300 \mathrm{~s}$. In EDTA experiments no perceptible change in light transmission occurred upon addition of SP-Ds. In the tracing designated "Maltose," $586 \mathrm{ng} / \mathrm{ml}$ of rat SP-D (in TBS with $\mathrm{Ca}^{2+}$ ) which had been pre-incubated with 167 $\mathrm{mM}$ maltose was added at $300 \mathrm{~s}$. No perceptible response to the SP-D occurred in this setting. 

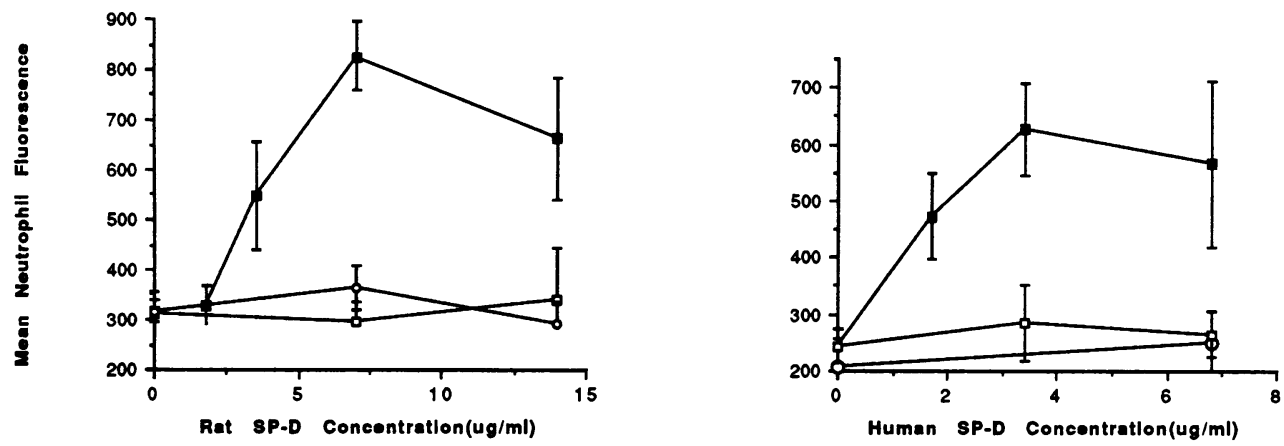

Figure 4. SP-D enhances IAV binding to neutrophils. Mean neutrophil fluorescence after exposure to FITC-labeled IAV (Bangkok 79 strain) alone, or FITC-labeled IAV which had been pre-incubated with various concentrations of SP-D, is shown. Results of experiments using native rat and human SP-D are depicted, respectively, in the left and right panels. The same IAV + SP-D samples were used in these experiments as those described in Fig. 1. The concentrations of SP-D are those that were originally present upon incubation with virus. A 10-fold dilution was made upon addition of these IAV + SP-D samples to the neutrophil suspension. Dark squares represent experiments carried out in $2 \mathrm{mM} \mathrm{Ca}^{2+}$-containing TBS. Open squares represent experiments carried out with SP-D which had been pre-incubated with $167 \mathrm{mM}$ maltose before addition to virus. Open circles represent experiments carried out in TBS containing $10 \mathrm{mM}$ EDTA. Results represent mean \pm SEM of 3-4 experiments. Mean neutrophil fluorescence was significantly increased $(P \leq 0.05)$ when virus samples which had been pre-incubated with 3.5 or $7 \mu \mathrm{g} / \mathrm{ml}$ of rat SP-D in $\mathrm{Ca}^{2+}$-containing buffer. Concentrations of 1.7 and $3.5 \mu \mathrm{g} / \mathrm{ml}$ of human SP-D significantly $(P \leq 0.025)$ increased viral binding. These effects were not seen when either rat or human SPD was pre-incubated with maltose, or when experiments were conducted in EDTA containing buffer. Note that SP-Ds were pre-incubated with IAV before addition to neutrophils in these experiments. When IAV was allowed to bind to neutrophils prior to addition of SP-D the lectin did not alter viral binding (data not shown).

of SP-Ds to cause viral aggregation. Neither native rat nor human SP-D was found to elicit $\mathrm{H}_{2} \mathrm{O}_{2}$ production on their own at these concentrations (data not shown).

$S P-D$ protects neutrophils against deactivation caused by $I A V$. Treatment of neutrophils with a wide variety of IAV strains results in impaired responsiveness of the cells to subsequent stimulation with various agonists $(21,30)$. The impairment, which we refer to as deactivation, involves chemotactic, respiratory burst, degranulation, and intracellular bacterial killing functions of the neutrophil. We have previously reported that preincubation of IAV with either conglutinin or MBL significantly reduces deactivation caused by the virus $(10,11)$. Using an



Figure 5. Rat SP-D enhances neutrophil activation by IAV. Neutrophil $\mathrm{H}_{2} \mathrm{O}_{2}$ responses elicited by Texas $77 \mathrm{IAV}$ alone, or the same amount of virus which had been incubated with various concentrations of native rat SP-D, are shown. The same samples used in Fig. 2 to assess aggregation of Texas $77 \mathrm{IAV}$ were used in these experiments. The original virus + SP-D samples were diluted from 1.5 to $2 \mathrm{ml}$ by the addition of 0.5 $\mathrm{ml}$ of the same buffer used in Fig. 2 (i.e., either TBS with $\mathrm{Ca}^{2+} 2 \mathrm{mM}$ [closed squares] or with EDTA $10 \mathrm{mM}$ [open circles]) containing 4 $\times 10^{6}$ neutrophils. Open squares again represent maltose treated SP-D samples. Results represent mean \pm SEM of three experiments for virus alone and virus treated with $367 \mathrm{ng} / \mathrm{ml}$ of SP-D (where $\mathrm{H}_{2} \mathrm{O}_{2}$ production was significantly increased; $P \leq 0.01$ ), and two experiments for other data points. assay for superoxide $\left(\mathrm{O}_{2}^{-}\right)$production in response to FMLP as an index of deactivation, native rat SP-D was similarly protective (see Fig. 7). The neutrophils were first incubated for 10 min with Bangkok 79 IAV alone, or the same amount of IAV which had been pre-incubated with various concentrations of SP-D. FMLP ( final concentration $10^{-7} \mathrm{M}$ ) was then added and the resulting $\mathrm{O}_{2}^{-}$response measured. Neutrophils which had been treated with IAV showed a significantly reduced $\mathrm{O}_{2}^{-}$response to FMLP compared to cells not exposed to virus. Neutrophils treated with IAV complexed with SP-D had a significantly greater $\mathrm{O}_{2}^{-}$response to FMLP than did those treated with IAV

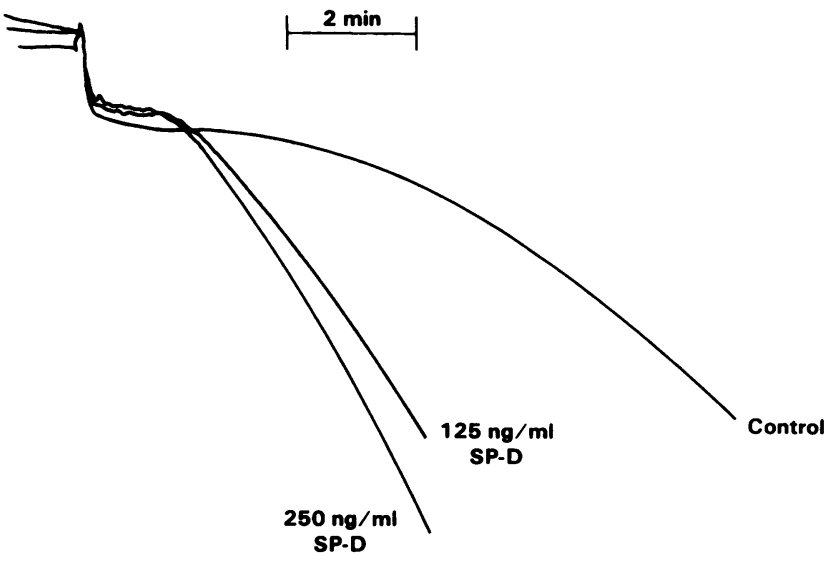

Figure 6. Human SP-D augments neutrophil activation by IAV. Representative scopoletin fluorescence tracings are shown. A suspension of neutrophils was added (where abrupt downward deflection occurs) to solutions of TBS (with $2 \mathrm{mM} \mathrm{Ca}^{2+}$ ) containing Texas 77 IAV alone (Control) or IAV which had been pre-incubated with either 125 or 250 $\mathrm{ng} / \mathrm{ml}$ of human SP-D, as indicated. These tracings are representative of three or six (for the $250 \mathrm{ng} / \mathrm{ml}$ concentration) similar experiments. In these experiments pre-incubation of IAV with either 125 or 250 $\mathrm{ng} / \mathrm{ml}$ of SP-D significantly increased the neutrophil $\mathrm{H}_{2} \mathrm{O}_{2}$ response $(P \leq 0.025)$. No enhanced response was observed in similar experiments carried out in $10 \mathrm{mM}$ EDTA (data not shown). 


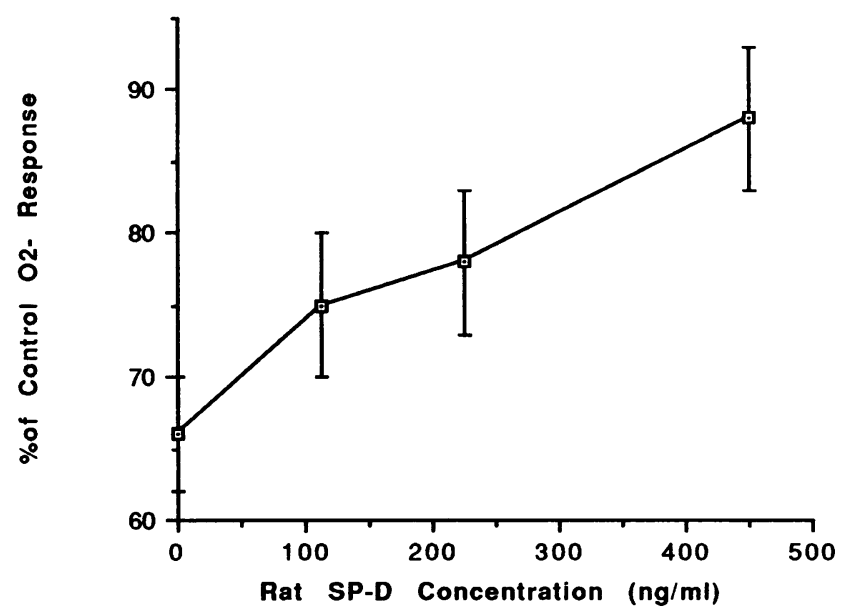

Figure 7. SP-D protects neutrophils against deactivation by IAV. Neutrophils were treated with control buffer, Bangkok 79 IAV alone (320 $\mathrm{HAU} / \mathrm{ml}$ ) or the same amount of virus which had been pre-incubated for 20 min with various concentrations of native rat SP-D as indicated. FMLP $\left(10^{-7} \mathrm{M}\right)$ was then added to all samples and the resulting superoxide response over $10 \mathrm{~min}$ measured using a continuous cytochrome $\mathrm{C}$ assay. The amount of superoxide produced in neutrophils treated with IAV preparations was divided by the amount produced in neutrophils not exposed to IAV to obtain the percent of Control $\mathrm{O}_{2}^{-}$. Results represent mean \pm SEM of four experiments. Significantly more superoxide ( $P$ $\leq 0.05$ ) was produced in response to FMLP in all samples containing SP-D, as compared to that produced in samples treated with IAV alone.

alone. No $\mathrm{O}_{2}^{-}$was generated during incubation of the neutrophils with IAV alone, or IAV complexed with SP-D (data not shown).

Addition of $440 \mathrm{ng} / \mathrm{ml}$ (final concentration) of native rat SP-D alone to neutrophils followed after $10 \mathrm{~min}$ by addition of FMLP led to a slight enhancement of the neutrophil $\mathrm{O}_{2}^{-}$response to FMLP $(9 \pm 2 \%$ increase; $n=3 ; P \leq 0.01)$ as compared to control neutrophils. When FITC-labeled Bangkok 79 IAV was pre-incubated with this concentration of rat SP-D followed by addition of neutrophils to this mixture, the $\mathrm{O}_{2}^{-}$ response to FMLP was increased by $31 \pm 4 \%$ as compared with cells treated with IAV alone $(n=4 ; P \leq 0.05)$. The SP-Dopsonized IAV preparation also showed significantly enhanced binding to neutrophils $(37 \pm 7 \% ; n=4 ; P \leq 0.005)$ compared to unopsonized IAV.

HA inhibitory activity of human bronchoalveolar lavage (BAL) fluids. An ELISA assay was developed to measure SP$D$ levels in BAL fluids obtained from healthy volunteer donors. We first measured the levels of SP-D present in BAL which had only been subjected to a $150 \mathrm{~g}$ centrifugation (hence still containing surfactant). The mean SP-D concentration in BAL fluid samples obtained from five donors was $139 \pm 29 \mathrm{ng} / \mathrm{ml}$. The total protein concentration for these BAL fluid samples was $34 \pm 10 \mu \mathrm{g} / \mathrm{ml}$. SP-D represented $0.5 \pm 0.1 \%$ of the total protein in these samples. The anti-SP-D immunoglobulin preparation at the dilution used in this assay had no significant reactivity with purified human SP-A. These SP-D values are similar to those that have previously been reported (18). We then subjected the BAL samples to a $10,000 \mathrm{~g}$ centrifugation. The vast majority of SP-A (99\%) is insoluble and is concentrated in the surfactant pellet by this maneuver (31). The mean \pm SEM SP-D level of the $10,000 g$ supernatant was
$104 \pm 31 \mathrm{ng} / \mathrm{ml}$. Hence, as previously reported $(18,31)$ the majority of SP-D is soluble and not surfactant-associated. Based on our findings using purified SP-Ds, the concentrations of SPD present in these BAL samples would be sufficient to show functional activity vs. IAV.

SP-D present in whole BAL bound to IAV as assessed using a dot blot assay (Fig. 8, Panel A). Sufficient SP-D was also present in the $10,000 \mathrm{~g}$ supernatant of BAL to show comparable binding to IAV (Fig. 8, Panel B). No binding of SP-D in BAL to control buffer alone or to BSA was detected. Nonspecific binding of immunoglobulins to the virus was also ruled out. Table II shows that the BAL samples also exhibited substantial HA inhibiting activity. Inclusion of maltose during the HA assay

\section{INFLUENZA A TITER \\ UD; $1: 2 ; 1: 4 ; 1: 8 ; 1: 16$}

$\mathbf{A}$

Binding Proteins

1) Human SP-D
$(200 \mathrm{ng} / \mathrm{ml})$

2) BAL fluid

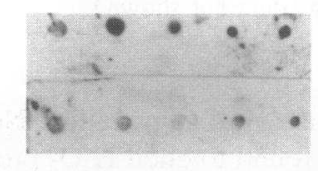
INFLUENZA A TITER
$\begin{aligned} & 1 ; 16 ; 1: 32 ; \text { buffer; BSA } \\ & \text { alone }\end{aligned}$

Binding Proteins

1) BAL (Pre-adsorption)

2) BAL (Post-adsorption)

3) IgG alone (control)

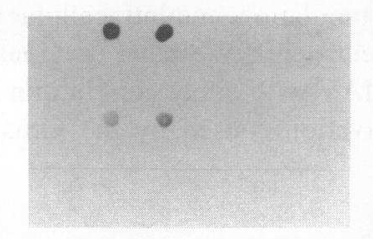

Figure 8. Dot blot assay demonstrating binding of SP-D contained in whole human bronchoalveolar lavage fluids to IAV. Various dilutions of Mem7 $71_{\mathrm{H}}-\mathrm{Be} 1_{\mathrm{N}}$ IAV was blotted on to nitrocellulose and the blots were exposed to purified native human SP-D (Human SP-D), BAL fluids, or control buffer. After washing, blots were incubated with rabbit anti-human SP-D IgG followed by goat anti-rabbit IgG coupled to HRP as described in Methods. The figure depicts photographic film exposed to the blots after addition of substrate to produce a chemiluminescence reaction over areas where HRP was bound. $A$ shows binding of human SP-D or SP-D present in the $150 \mathrm{~g}$ supernatant of BAL fluid to various dilutions of IAV (from undiluted $[U D]$ to a 1:16 dilution). The undiluted IAV stock contained 32,000 HAU/ml and $1 \mathrm{mg} / \mathrm{ml}$ of protein. $B$ assesses binding of SP-D present in BAL to IAV diluted either 16- or 32-fold, or to buffer or BSA $(200 \mu \mathrm{g} / \mathrm{ml})$ alone (i.e., no virus present in the latter two lanes). Note that SP-D in BAL did not bind to BSA ( $200 \mu \mathrm{g} / \mathrm{ml})$ alone or buffer alone. Purified SP-D also did not bind in this setting (data not shown). In row 1 the supernatant of BAL which had been subjected to a $10,000 \mathrm{~g}$ centrifugation (to remove surfactant and SP-A) was used (denoted as BAL [pre-adsorption]). In row 2 the same BAL supernatant was used, but after it had been adsorbed with a maltosyl-agarose column (BAL [post-adsorption]) to reduce the amount of SP-D present (see text). The amount of total BAL protein used was the same in rows 1 and 2 (i.e., $100 \mu \mathrm{g} / \mathrm{ml}$ ). In row 3 , blots were incubated with buffer only (instead of BAL), followed by addition of antibodies ( $I g G$ alone). No chemiluminescence was evident in this row. 
Table II. Inhibition of IAV Hemagglutination Activity by Bronchoalveolar Lavage Fluids, SP-D, or SP-A

\begin{tabular}{|c|c|c|}
\hline & \multicolumn{2}{|c|}{$\begin{array}{l}\text { Percent reduction in HA titer in } \\
\text { BAL- or SP-A-treated samples }\end{array}$} \\
\hline & $\mathrm{TBS}+\mathrm{Ca}^{2+}$ & $\begin{array}{l}\text { TBS }+\mathrm{Ca}^{2+} \\
+ \text { maltose }\end{array}$ \\
\hline BAL $150 \mathrm{~g}$ supernatant & $86 \pm 3 \%$ & $50 \pm 14 \% *$ \\
\hline BAL $10,000 \mathrm{~g}$ supernatant & $69 \pm 6 \% \%^{\ddagger}$ & \\
\hline SP-A $3.8 \mu \mathrm{g} / \mathrm{ml}$ & $59 \pm 6 \%$ & $61 \pm 8 \%$ \\
\hline SP-A $7.6 \mu \mathrm{g} / \mathrm{ml}$ & $81 \pm 4 \%$ & $76 \pm 8 \%$ \\
\hline SP-D $113 \mathrm{ng} / \mathrm{ml}$ & $50 \pm 0 \%$ & $0 \%$ \\
\hline SP-D $225 \mathrm{ng} / \mathrm{ml}$ & $56 \pm 6 \%$ & $0 \% *$ \\
\hline SP-D $450 \mathrm{ng} / \mathrm{ml}$ & $84 \pm 3 \%$ & $0 \% *$ \\
\hline SP-A $3.8 \mu \mathrm{g} / \mathrm{ml}+$ SP-D $113 \mathrm{ng} / \mathrm{ml}$ & $69 \pm 6 \%$ & \\
\hline SP-A $3.8 \mu \mathrm{g} / \mathrm{ml}+$ SP-D $225 \mathrm{ng} / \mathrm{ml}$ & $78 \pm 3 \% 8$ & \\
\hline
\end{tabular}

IAV samples $\left(2,400 \mathrm{HAU} / \mathrm{ml}\right.$ of $\mathrm{Mem} 71_{\mathrm{H}^{-}}-\mathrm{Bel}_{\mathrm{N}}$ strain) were preincubated in control buffer or buffer containing either bronchoalveolar lavage fluid $(B A L)$ from healthy volunteer donors ( $n=5$ separate donors used), purified SP-A or purified human SP-D at the indicated concentrations. "BAL $150 \mathrm{~g}$ Supernatant" and "BAL 10,000 g supernatant" refer to the supernatant remaining after subjecting the BAL fluid to a either 150 or $10,000 \mathrm{~g}$ centrifugation for $1 \mathrm{~h}$. Values represent mean \pm SEM percent inhibition of control HA titers (i.e., HA titer of BAL-, SP-A-, or SPD-treated sample/HA titer of control sample $\times 100)(n=3-6$ experiments). Where indicated BAL or SP-D was pre-incubated with a final concentration of $167 \mathrm{mM}$ maltose before addition of IAV. When incubated in TBS $+\mathrm{Ca}^{2+}$ (without maltose), HA titers in all BAL-, SP-A-, or SP-D-treated samples were significantly reduced compared with control. * Significantly less inhibition $(P \leq 0.05)$ compared to BAL or SP-D without maltose. ${ }^{\ddagger}$ Significantly less inhibition $(P \leq 0.05)$ compared to BAL before $10,000 \mathrm{~g}$ centrifugation. ${ }^{8}$ Significantly more inhibition $(P \leq 0.005)$ compared with either SP-A or SP-D alone at the same concentrations.

significantly (although incompletely) reduced the HA inhibitory activity of the BAL.

SP-A has been reported to have anti-IAV activity (32). However, SP-A on its own is unlikely to have been responsible for the majority of HA inhibiting activity in BAL (Table II). The average concentration of SP-A present in the $150 \mathrm{~g}$ supernatant of BAL fluid has been determined to be approximately $0.83 \mu \mathrm{g} / \mathrm{ml}$ (33). Using purified, solubilized SP-A, substantially higher concentrations of SP-A were required to achieve a degree of HA inhibition comparable to that obtained using the $150 \mathrm{~g}$ supernatant of BAL (Table II). The HA inhibiting effects of SP-A were not statistically significantly reduced by addition of maltose to the assay (while, as expected, maltose completely prevented SP-D from exerting HA inhibiting effects). Furthermore, the $10,000 \mathrm{~g}$ supernatant of BAL (which contains minimal amounts of SP-A) retained substantial HA inhibitory activity. Note that SP-D was more than tenfold as potent as SP-A at inhibiting HA activity, and that SP-D exhibited additive HAinhibiting effects when added simultaneously with SP-A (Table II).

To confirm that SP-D contributes to the overall HA inhibitory activity of BAL, we adsorbed the $10,000 \mathrm{~g}$ supernatant of BAL with maltosyl-agarose. Pre- and post-adsorption samples were adjusted to have the same total protein concentration by use of Centricon microconcentrators (Amicon Co., Beverly,

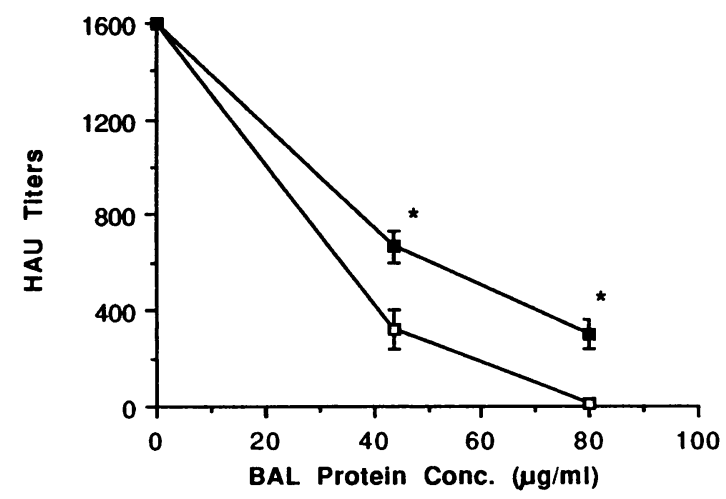

Figure 9. Inhibition of IAV HA activity caused by BAL fluid before and after adsorption by maltosyl-agarose. The $10,000 \mathrm{~g}$ BAL supernatant pre- and post-adsorption by maltosyl-agarose (prepared as described in Fig. $8 B$ and in text) was tested for its ability to inhibit HA activity of the $\mathrm{Mem}_{\mathrm{H}}-\mathrm{Be} 1_{\mathrm{N}}$ strain of IAV. BAL pre-adsorption is shown with open squares; post-adsorption BAL is shown with dark squares. The $\mu \mathrm{g} / \mathrm{ml}$ of total BAL protein added is shown on the horizontal axis. $(*)$ Statistically significant reduction $(P \leq 0.025)$ in ability of post-adsorption BAL to inhibit HA activity.

MA). The EDTA eluate from the maltosyl-agarose contained SP-D based on immunoblot (data not shown). SDS-PAGE analysis of the BAL fluid prior to passage through the maltosylagarose column was compared to that of the column flowthrough and no apparent difference in any major protein bands was seen (data not shown). SP-D levels were too low to be detected on Coomassie blue staining. However, using the ELISA assay for SP-D, the maltosyl-agarose adsorption reduced immunoreactive SP-D by 90\% (from 69 to $7 \mathrm{ng} / \mathrm{ml}$ ). This adsorption significantly reduced the HA inhibitory activity of the supernatant as shown in Fig. 9. As shown in Fig. 8, maltosylagarose adsorption also substantially reduced the SP-D available to bind to IAV as assessed by the dot blot assay.

\section{Discussion}

IAVs are major human and animal pathogens which undergo rapid evolution in their HA genes, enabling them to evade specific cell- and antibody-mediated immune responses (34). Given the substantial morbidity and mortality associated with influenza epidemics, it seems plausible that nonspecific, or "natural," host defense mechanisms may have evolved to protect against these viruses (35). The host response to IAV that occurs prior to the development of specific antibody and cellmediated immunity is generally successful in that the virus remains confined to the upper respiratory tract, with viremia and viral pneumonia being uncommon (36). We have previously summarized data which support the contention that phagocytes (including neutrophils and macrophages) play a role in the early host defense against IAV infection (37). Also, bacterial superinfection, possibly resulting from IAV-induced phagocyte dysfunction, is the most important cause of morbidity and mortality during IAV epidemics (38). The findings presented herein suggest that the surfactant protein D may, by itself and in combination with phagocytes, also contribute to the initial host defense against IAV. This protein is particularly well situated to protect the lower respiratory tract from invasion by IAV.

SP-D of rat or human origin potently inhibits hemagglutina- 
tion activity of a variety of IAV strains, including representatives of the two major subtypes currently circulating in the human population (i.e., H1 and H3). SP-D is also shown to cause aggregation of IAV particles. These effects are mediated through binding of the SP-D carbohydrate recognition domain to viral carbohydrates, as demonstrated by inhibition with maltose or $\mathrm{Ca}^{2+}$-chelation. The lack of effect of SP-D on the PR8 strain of IAV, which lacks glycosylation on the globular head of the HA (28) provides further evidence in support of this interpretation. Aggregation of viral particles by SP-D may reduce infectious particle numbers and enhance clearance by mucociliary and phagocytic mechanisms. Neutrophils bind IAV to a greater extent when the virus is complexed with SP-D, perhaps in part due to viral aggregation. The concentrations of human or rat SP-D which cause enhanced respiratory burst responses parallel those which cause viral aggregation. This is consistent with the prior observation that larger IAV particles are a more effective stimulus for phagocyte respiratory burst activation (39). Pre-incubation of IAV with SP-D also protects the cells against the deactivating effects of the virus. These results imply that opsonization of the virus with SP-D enabled the neutrophil to process the virus in a manner less deleterious to the cell. This effect suggests that SP-D may be protective against bacterial superinfection in vivo.

The concentrations of SP-D required to mediate inhibition of IAV HA activity, or cause IAV aggregation are within the range of concentrations found in BAL fluids. Local concentrations in the lung are certainly considerably higher than those found in unconcentrated BAL fluid. SP-A also inhibited IAV HA activity, although SP-A was more than 10-fold less potent than SP-D in this regard. Inhibition of IAV infectivity by similar concentrations of SP-A was recently reported by van Iwaarden et al. (32) as well. SP-D and SP-A exist in different compartments in vivo, with SP-D being largely soluble, while SP-A is largely surfactant-associated. Since SP-A levels in whole BAL fluid exceed those of SP-D by $\sim 10$-fold, it may be that both lectins contribute to IAV inhibitory activity in a cooperative manner (see Table II), with the former acting principally at the surfactant interface, and the latter in the fluid phase of the airways.

The serum proteins MBL and conglutinin, which bear significant homology to SP-D, also have similar ability to inhibit HA activity and enhance neutrophil responses upon exposure to the virus $(10,11)$. Of note, SP-D exceeds these serum lectins in potency in these assays. Concentrations of $\mathrm{MBL}$ are required to achieve similar HA inhibition, or respiratory burst enhancement exceed those of SP-D by 10 -fold or more. While the HA inhibitory potency of conglutinin is similar to that of SP-D, to achieve optimal IAV aggregation or neutrophil respiratory burst enhancement $1.5 \mu \mathrm{g} / \mathrm{ml}$ (final concentration) of conglutinin are required as compared to between 250 and $500 \mathrm{ng} / \mathrm{ml}$ of SP-Ds. SP-D is also more potent than MBL or conglutinin at protecting neutrophils from deactivation by IAV. The lesser potency of MBL and SP-A as compared to SP-D and conglutinin may, in part, be attributable to the smaller size of the former molecules. It should be noted that SP-A and SP-D obtained from patients with alveolar proteinosis may differ in some respects from SPA or SP-D present in normal donors. In any case, our finding that silicotic and recombinant rat SP-D and SP-D present in normal donor BAL had similar anti-IAV activities as the alveolar proteinosis proteins suggests that our results are not attributable to aberrancies of the latter preparations.
A thorough understanding of lectin interactions with IAV may allow prediction of which viral strains are likely to be most virulent in vivo, or which hosts may be particularly vulnerable to adverse sequelae of influenza. It may be that strains of IAV with glycosylation patterns that do not allow lectin binding to the virus are more capable of causing viral pneumonia, viral infection of extrapulmonary tissues, or phagocyte deactivation and bacterial superinfection. Better understanding of the preimmune host response to IAV may lead to ways of predicting which patients are most at risk for complications of influenza (e.g., because of congenital or acquired differences in lectin production) and possibly to new modes of therapeutic intervention.

\section{Acknowledgments}

We wish to thank Ann Marie Happnie for assistance in the preparation of the manuscript, Dr. Paul Meers for assistance in devising the assay of viral aggregation, and Drs. Chris Reardon and Jussi Saukonen for providing bronchoalveolar lavage samples.

This study was supported by National Institutes of Health grants: AI29550-03 (K. L. Hartshorn), HL335565-08 (A. I. Tauber), AI3313001 (K. Sastry), and HL44015-04 (E. Crouch).

\section{References}

1. Thiel, S., and K. B. M. Reid. 1989. Structures and functions associated with the group of mammalian lectins containing collagen-like sequences. FEBS (Fed. Eur. Biochem. Soc.) Lett. 250:78-84.

2. Sastry, K., and R. A. Ezekowitz. 1993. Collectins: pattern recognition molecules involved in first line host defense. Curr. Opin. Immunol. 5:59-66.

3. Friis-Christiansen, P., S. Thiel, S.-E. Svehag, R. Dessau, P. Svendsen, O. Andersen, S. B. Laursen, and J. Chr. Jensenius. 1990. In vivo and in vitro antibacterial activity of conglutinin, A mammalian plasma lectin. Scand. J. Immunol. $31: 453-460$.

4. Andersen, O., A.-M. Sorensen, S.-E. Svehag, and E. Fenouillet. 1991. Conglutinin binds the HIV-1 envelope glycoprotein gp 160 and inhibits its interaction with cell membrane CD4. Scand. J. Immunol. 33:81-88.

5. Ezekowitz, R. A. B., M. Kuhlman, J. E. Groopman, and R. A. Byrn. 1989 A human serum mannose-binding protein inhibits in vitro infection by the human immunodeficiency virus. J. Exp. Med. 169:185-196.

6. van Iwaarden, J. F., J. A. G. van Strijp, H. Visser, H. P. Haagsman, J. Verhoef, and L. M. G. van Golde. 1992. Binding of surfactant protein A (SP-A) to herpes simplex virus type 1-infected cells is mediated by the carbohydrate moiety of SP-A. J. Biol. Chem. 267:25039-25043.

7. McNeely, T. B., and J. D. Coonrod. 1993. Comparison of the opsonic activity of human surfactant protein A for Staphylococcus aureus and Streptococcus pneumoniae with rabbit and human macrophages. J. Infect. Dis. 167:91-97.

8. Kuan, S.-F., K. Rust, and E. Crouch. 1992. Interactions of surfactant protein D with bacterial lipopolysaccharides. Surfactant protein D is an Escherichia Colibinding protein in bronchoalveolar lavage. J. Clin. Invest. 90:97-106.

9. van Iwaarden, J. F., H. Shimizu, P. H. M. Van Golde, D. R. Voelker, and L. M. G. Van Golde. 1992. Rat surfactant protein D enhances the production of oxygen radicals by rat alveolar macrophages. Biochem. J. 286:5-8.

10. Hartshorn, K. L., K. Sastry, M. R. White, E. M. Anders, M. Super, R. A. Ezekowitz, and A. I. Tauber. 1993. Human mannose-binding protein functions as an opsonin for influenza A viruses. J. Clin. Invest. 91:1414-1420.

11. Hartshorn, K. L., K. Sastry, D. Brown, M. R. White, T. B. Okarma, Y. M. Lee, and A. I. Tauber. 1993. Conglutinin acts as an opsonin for influenza A viruses. J. Immunol. 151:6265-6273.

12. Lu, J., A. C. Willis, and K. B. M. Reid. 1992. Purification, characterization and cDNA cloning of human lung surfactant protein D. Biochem. J. 284:795802.

13. Liou, L., R. Sastry, K. L. Hartshorn, A. I. Tauber, and K. Sastry. 1994. Bovine conglutinin mRNA is expressed in liver: cloning and characterization reveals strong homology to surfactant protein D. Gene. 141:277-281.

14. Crouch, E., D. Parghi, S-F. Kuan, and A. Persson. 1992. Surfactant protein D: subcellular localization in nonciliated bronchiolar epithelial cells. Am. Physiol. Soc. 263:L61-L66.

15. Malhotra, R., S. Thiel, K. B. M. Reid, and R. B. Sim. 1990. Human leukocyte $\mathrm{Clq}$ receptor binds other soluble proteins with collagen domains. $J$. Exp. Med. 172:955-959.

16. Kuan, S-F. A. Persson, D. Parghi, and E. C. Crouch. 1994. Lectin-mediated 
interactions of surfactant protein D with alveolar macrophages. Am. J. Respir. Cell Mol. Biol. 10:430-436.

17. Crouch, E., A. Persson, D. Chang, and D. Parghi. 1991. Surfactant protein D. Increased accumulation in silica-induced pulmonary lipoproteinosis. Am. J. Pathol. 139:765-776.

18. Crouch, E., A. Persson, and D. Chang. 1993. Accumulation of surfactant protein D in human pulmonary alveolar proteinosis. Am. J. Pathol. 142:241-248.

19. Wright, J. R., R. E. Wager, S. Hawgood, L. Dobbs, and J. A. Clements. 1987. Surfactant apoprotein $M_{r}=26,000-36,000$ enhances uptake of liposomes by Type II cells. J. Biol. Chem. 262:2888-2894.

20. Ross, G. F., B. L. Ohning, D. Tannenbaum, and J. Whitsett. 1987. Structural relationships of the major glycoproteins from human alveolar proteinosis surfactant. Biochim. Biophys. Acta. 911:294-305.

21. Hartshorn, K. L., M. Collamer, M. Auerbach, J. B. Myers, N. Pavlotsky, and A. I. Tauber. 1988. Effects of influenza A virus on human neutrophil calcium metabolism. J. Immunol. 141:1295-1301.

22. Arora, D. J. S., P. Tremblay, R. Bourgault, and S. Boileau. 1985. Concentration and purification of influenza virus from allantoic fluid. Anal. Biochem. 144:189-192.

23. Hartley, C. A., D. C. Jackson, and E. M. Anders. 1992. Two distinct serum mannose-binding lectins function as beta inhibitors of influenza virus: Identification of bovine serum beta inhibitor as conglutinin. J. Virol. 66:43584363.

24. Meers, P., T. Mealy, N. Pavlotsky, and A. I. Tauber. 1992. Annexin I-mediated vesicular aggregation: Mechanism and role in human neutrophils. Biochemistry. 31:6372-6382.

25. Chong, C. S., and K. Colbow. 1976. Light scattering and turbidity measurements on lipid vesicles. Biochim. Biophys. Acta. 436:260-282.

26. Hartshorn, K. L., M. Collamer, M. R. White, J. H. Schwartz, and A. I. Tauber. 1990. Characterization of influenza A virus activation of the human neutrophil. Blood. 75:218-226.

27. Caton, A. J., G. G. Brownlee, J. W. Yewdell, and W. Gerhard. 1982
The antigenic structure of the influenza Virus A/PR/8/34 hemagglutinin ( $H 1$ subtype). Cell. 31:417-425.

28. Schwartz, R. T., and H-D. Klenk. 1981. Carbohydrates of influenza virus IV. Strain-dependent variations. Virology. 113:584-593.

29. Anders, E. M., C. A. Hartley, and D. C. Jackson. 1990. Bovine and mouse serum beta inhibitors of the influenza $A$ viruses are mannose-binding lectins. Proc. Natl. Acad. Sci. USA. 87:4485-4489.

30. Hartshorn, K. L., and A. I. Tauber. 1988. The influenza virus-infected phagocyte. A model of deactivation. Hemat. Oncol. Clin. N. Am. 2:301-315.

31. Kuroki, Y., M. Shiratori, Y. Ogasawara, A. Tsuzuki, and T. Akino. 1991 Characterization of pulmonary surfactant protein D: its co-purification with lipids. Biochim. Biophys. Acta. 1086:185-190.

32. van Iwaarden, J. F., C. A. Benne, J. A. G. van Strijp, J. Verhoef, L. M. G. van Golde, and C. A. Kraaijeveld. 1993. Surfactant protein A prevents infection of cells by influenza A virus. Am. Rev. Respir. Dis. 148:146(a) Abstr.

33. McCormack, F. X., T. E. King, D. R. Voelker, P. C. Robinson, and R. J. Mason. 1991. Idiopathic pulmonary fibrosis: abnormalities in the bronchoalveolar content of surfactant protein A. Am. Rev. Resp. Dis. 144:160-166.

34. Wiley, D. C. 1987. The structure and function of the hemagglutinin membrane glycoprotein of influenza virus. Ann. Rev. Biochem. 56:365-394.

35. Hartshorn, K. L., A. B. Karnad, and A. I. Tauber. 1990. Influenza A virus and the neutrophil: a model of natural immunity. J. Leukocyte Biol. 47:176-186.

36. Sweet, C., and H. Smith. 1980. Pathogenicity of influenza virus. Microbiol ogy. 44:303-330.

37. Hartshorn, K. L., D. Daigneault, and A. I. Tauber. 1992. Phagocyte responses to viral infection. In Inflammation: Basic Principles and Clinical Correlates, Second Edition. J. I. Gallin, I. M. Goldstein, and R. Snyderman, eds. Raven Press, Ltd., NY. 1017-1031.

38. Kilbourne, E. D. 1987. Influenza. Plenum Publishing Corp., NY.

39. Peterhans, E., F. Mettler, and E. Manser. 1990. The effect of virus particle size on chemiluminescence induction by influenza and Sendai viruses in mouse spleen cells. Free Rad. Res. Comms. 11:11-22. 